\title{
Comunicação
}

[Communication]

\section{Surto de mastite bovina causada por Arcanobacterium pyogenes}

[Outbreak of bovine mastitis caused by Arcanobacterium pyogenes]

R.G. Motta, M.G. Ribeiro, I.B.M. Perrotti, D.G. Motta, P.F. Domingues, T.M. Lucas, T.O. Zamprogna, F.J.P. Listoni

Faculdade de Medicina Veterinária e Zootecnia - UNESP

Caixa Postal 560,

18618-970 - Botucatu, SP

\begin{abstract}
Arcanobacterium pyogenes são bactérias encontradas nas membranas mucosas dos animais domésticos (Quinn et al., 2005), relacionadas a diferentes manifestações clínicas, que incluem: pneumonia, artrite, onfaloflebite, dermatite, endometrite, endocardite e abscessos em órgãos. As infecções mamárias em vacas por A. pyogenes são caracterizadas por processos purulentos, de difícil tratamento. São comumente reconhecidas como "mastite de verão", em virtude da veiculação do agente para as vacas por moscas, cuja proliferação é favorecida em períodos do ano com altas temperatura e pluviosidade (Radostits et al., 2007).
\end{abstract}

A mastite bovina por $A$. pyogenes acomete principalmente novilhas, vacas no período seco e, menos frequentemente, vacas em lactação (Radostits et al., 2007; Santos e Fonseca, 2007). No decorrer da lactação, as infecções em vacas ocorrem comumente nas primeiras semanas pósparto. A veiculação do microrganismo ocorre após contaminação do úbere e tetos por objetos perfurocortantes, por contaminação de ferimentos das mamas por moscas ou mesmo contaminação de utensílios de ordenha (Costa et al., 2000). A infecção mamária é mais frequente em locais com excesso de umidade, acúmulo de sujidades e matéria orgânica, particularmente no ambiente da pré e pós-ordenha, pela presença de lama, terra e dejetos (Domingues et al., 2008), caracterizando o microrganismo como agente ambiental na casuística da mastite bovina (Radostits et al., 2007). O hábito das novilhas de mamar entre si é reportado também como uma das principais formas de transmissão do microrganismo nesta categoria animal (Domingues et al., 2008).

A. pyogenes caracteriza-se por sinais de edema, formação de nódulos e abscessos isolados ou múltiplos nas mamas, e leite com presença de pus. Nos casos severos, ocorre formação de extensas áreas de abscessos com conteúdo purulento. Os abscessos mamários eventualmente expandem-se para os tecidos adjacentes da derme (Radostits et al., 2007). Ocasionalmente são observados também sinais sistêmicos, como febre, agalaxia e anorexia (Costa et al., 2000). O microrganismo revela certa sensibilidade aos antimicrobianos nos testes in vitro. No entanto, geralmente é refratário aos tratamentos intramamários e/ou parenterais nas infecções mamárias. Dessa forma, comumente recomenda-se a ablação química dos quartos acometidos (Ribeiro, 2008).

O presente estudo investigou um surto de mastite bovina causada por A. pyogenes em uma propriedade leiteira no município de Angatuba, SP, entre os meses de janeiro e fevereiro de 2010, a qual apresentava histórico de aumento súbito na ocorrência de mastite clínica, aliado a baixa eficiência do tratamento intramamário das vacas. O rebanho era constituído de 332 animais da raça Holandesa, sendo 217 vacas em lactação e produção diária de leite de 3.900. Os animais eram criados em sistema semi-intesivo, com ordenha mecânica do tipo "espinha de peixe". O período do surto de mastite foi marcado por 
intensa precipitação pluviométrica, que culminou com excesso de umidade e acúmulo de barro nas imediações da sala de ordenha.

Procedeu-se ao exame das glândulas mamárias e ao consequente diagnóstico de mastite clínica, firmado nos animais que apresentaram alterações no leite - presença de grumos, pus, dessora ou estrias de sangue - ao teste da caneca telada de fundo escuro (Tamis), sinais de inflamação na glândula mamária - dor, edema, hiperemia ou nódulos - e sinais sistêmicos. A mastite subclínica foi caracterizada utilizandose o teste clássico de California Mastitis TestCMT, escores 1+ a 3+ (Radostits et al., 2007). Simultaneamente, foi colhido leite das vacas pool dos quatro quartos - para avaliação da contagem eletrônica de células somáticas (CCS). O material, acondicionado em frascos apropriados contendo o conservante bronopol, foi encaminhado em até 48 horas para a Clínica do Leite da Esalq-USP, Piracicaba, SP, e avaliado pelo equipamento SomaCount 500, pelo método de citometria de fluxo.

Foram colhidas assepticamente 597 amostras de leite de quartos mamários de 217 vacas em lactação e mantidas em temperatura de refrigeração $\left(4\right.$ a $\left.8^{\circ} \mathrm{C}\right)$ por 24 horas até o processamento. Todas as amostras de leite foram semeadas em ágar-sangue bovino desfibrinado (5\%) e ágar MacConkey, incubadas em aerobiose, a $37^{\circ} \mathrm{C}$, por 72 horas. Os microrganismos isolados foram identificados com base nas características morfo-tintoriais, bioquímicas e de cultivo (Quinn et al., 2005). O perfil de sensibilidade microbiana dos isolados foi realizado pela técnica de difusão com discos segundo o CLSI (Performance..., 2003), utilizando-se antimicrobianos disponíveis comercialmente para a terapia intramamária em vacas, a saber: amoxacilina $(10 \mu \mathrm{g})$, cefalexina $(30 \mu \mathrm{g})$, cefoperazona sódica $(75 \mu \mathrm{g})$, ceftiofur $(30 \mu \mathrm{g})$, enrofloxacina $(5 \mu \mathrm{g})$, espiramicina $(100 \mu \mathrm{g})$, florfenicol $(30 \mu \mathrm{g})$, gentamicina $(10 \mu \mathrm{g})$, neomicina (30 $\mathrm{g})$, penicilina (10UI) e tetraciclina $(30 \mu \mathrm{g})$.

Das 217 vacas em lactação, 38 (17,5\%) apresentaram mastite clínica, e 114 (52,5\%) subclínica. Nos animais com mastite clínica, foram observados: sensibilidade dolorosa acentuada à palpação da glândula mamária, presença de nódulos, abscessos isolados e múltiplos, e fístulas com drenagem de pus viscoso, esverdeado e de odor pútrido. A secreção láctea também mostrou aspecto purulento e odor desagradável. Em 26 (12,0\%) vacas, das quais 10 com mastite clínica e 16 com mastite subclínica (escores 1+ a 3+ no CMT), foram isoladas colônias diminutas, com 1-2mm de diâmetro, ß-hemolíticas, convexas, translúcidas, com 48 horas de incubação no meio de ágar-sangue. Na coloração de Gram, foram observados microrganismos pleomórificos, dispostos em arranjo de "paliçada” ou "letras chinesas”. O agente acusou reação negativa na prova de catalase e positiva no Camp Test frente ao Staphylococcus aureus. No ágar MacConkey, não houve isolamento bacteriano. Com base nestas características fenotípicas, o microrganismo foi classificado como $A$. pyogenes. Nos demais animais foram isolados os gêneros Staphylococcus, 56 quartos com mastite subclínica e nove com mastite clínica; Streptococcus, 28 casos subclínicos e três clínicos; Corynebacterium, 14 subclínicos, Enterobacter; cinco clínicos; e E. coli, 11 clínicos.

O perfil de sensibilidade microbiana dos 26 isolados de $A$. pyogenes revelou que cefoperazona (92,3\%), florfenicol (96,2\%), cefalexina $(84,6 \%)$ e ceftiofur $(84,6 \%)$ foram os antimicrobianos mais efetivos. Os maiores índices de resistência das estirpes foram observados para neomicina (27,0\%) e enrofloxacina (15,4\%) (Tab. 1). A média da celularidade no tanque de resfriamento dos 217 animais em lactação foi de $1.080 \mathrm{CS} / \mathrm{mL}$. Em contraste, a CCS dos 26 animais com isolamento de $A$. pyogenes acusou $2.273 \mathrm{CS} / \mathrm{mL}$, com variação de 989 a $4.321 \mathrm{CS} / \mathrm{mL}$. Os 10 animais com mastite clínica por $A$. pyogenes foram submetidos ao tratamento intramamário com produto comercial - associação de cefalexina e neomicina -, em duas aplicações diárias, com duração de cinco dias, resultando em sucesso terapêutico em somente três animais. Nos outros sete animais com mastite clínica por $A$. pyogenes, foi recomendada a ablação química dos quartos mamários, com infusão intramamária de iodo a 10\%, diluído em 100 mL de solução salina (0,85\%) estéril. 
Tabela 1. Perfil de sensibilidade microbiana na prova de difusão com discos em linhagens de Arcanobacterium pyogenes isoladas de surto de mastite bovina

\begin{tabular}{lccc}
\hline \multirow{2}{*}{ Antimicrobiano } & \multicolumn{3}{c}{ Número de linhagens (\%) } \\
\cline { 2 - 4 } & Sensível & Parcialmente sensível & Resistente \\
\hline Amoxacilina & $18(69,3)$ & $7(26,9)$ & $1(3,8)$ \\
Cefalexina & $22(84,6)$ & $3(11,5)$ & $1(3,8)$ \\
Cefoperazona & $24(92,3)$ & $1(3,8)$ & $1(3,8)$ \\
Ceftiofur & $22(84,6)$ & $4(15,4)$ & $0(--)$ \\
Enrofloxacina & $12(46,1)$ & $10(38,5)$ & $4(15,4)$ \\
Espiramicina & $21(80,8)$ & $5(19,2)$ & $0(--)$ \\
Florfenicol & $25(96,2)$ & $1(3,8)$ & $0(--)$ \\
Gentamicina & $21(80,8)$ & $4(15,4)$ & $1(3,8)$ \\
Neomicina & $6(23,0)$ & $13(50,0)$ & $7(27,0)$ \\
Penicilina & $21(80,8)$ & $2(7,7)$ & $3(11,5)$ \\
Tetracilicna & $19(73,1)$ & $4(15,4)$ & $3(11,5)$ \\
\hline
\end{tabular}

Raramente as infecções mamárias por A. pyogenes em vacas ocorrem em alta frequência nos rebanhos, tampouco sob a forma de surtos. Wilson et al. (1997) descreveram A. pyogenes em $0,3 \%$ da casuística de mastite em vacas nos EUA. No Brasil, estudo envolvendo a etiologia da mastite bovina verificou a participação de $A$. pyogenes em somente $0,4 \%$ de 736 dos casos (Costa et al., 1998). No presente estudo, A. pyogenes foi isolado de 26 dentre 217 animais em lactação, representando $12 \%$ de todo o efetivo do plantel, ou $17,1 \%$ dos casos de mastite clínica ou subclínica (26/152), caracterizando a participação incomum do microrganismo sob a forma de surto.

Dentre os 26 animais acometidos por $A$. pyogenes, 10 apresentaram a forma clínica reconhecida como apresentação clássica nas infecções mamárias em vacas, descritas tanto no Brasil (Domingues et al., 2008) como em outros países (Radostits et al., 2007), representada por queda abrupta da produção e sinais clínicos graves, como formação de nódulos, abscessos, áreas de necrose com trajetos fistulosos, presença de leite com pus e odor desagradável. Curiosamente, A. pyogenes acomete geralmente novilhas e vacas no período seco (Wilson et al., 1997; Costa et al., 2000), fato não observado nos animais reportados, que se encontravam exclusivamente em lactação. Ademais, no presente surto, foram encontrados 16 animais com mastite subclínica por A. pyogenes. Este achado também é pouco frequente nas mastites em vacas por A. pyogenes, pois, segundo Hillerton e Bramley (1989) esta bactéria raramente é isolada de animais em lactação na ausência de sinais clínicos.

A mastite bovina por A. pyogenes ocorre com maior frequência em períodos de altos índices pluviométricos e temperaturas elevadas, que favorecem condições climáticas para a proliferação de moscas, intimamente relacionadas com a veiculação do microrganismo para o úbere e tetos, das mucosas dos animais, da secreção purulenta de abscessos ou mesmo do próprio ambiente contaminado (Wilson et al., 1997; Hillerton e Berry, 2005). O surto relatado ocorreu entre os meses de janeiro e fevereiro de 2010, o que coincide com períodos quentes e chuvosos do ano na região, reforçando a denominação popular de "mastite de verão", em virtude de certa sazonalidade das infecções pelo microrganismo, neste período do ano.

A CCS constitui método indireto de diagnóstico da mastite, utilizado no monitoramento da saúde da glândula mamária de vacas, fundamentado na contagem de células inflamatórias - neutrófilos e epiteliais (Santos e Fonseca, 2007). A mediana da CCS observada nos animais identificados com mastite por A. pyogenes foi de 2.273.000 CS/mL. Este resultado encontra-se muito acima de 200250.000 ou $500.000 \mathrm{CS} / \mathrm{mL}$, considerados, respectivamente, os valores de normalidade e indicativos de infecção em vacas (Santos e Fonseca, 2007). A alta celularidade evidenciada nos animais infectados provavelmente decorre do intenso processo piogranulomatoso mamário induzido por $A$. pyogenes, caracterizado por alta quimiotaxia de neutrófilos, que tende a elevar 
significativamente a contagem celular do leite (Radostits et al., 2007).

Mesmo que o tratamento intramamário tenha sido feito em 10 animais, com base na sensibilidade à cefalexina no antibiograma, utilizando-se antimastítico disponível comercialmente, a cura só foi obtida em três (30\%) animais. Essa baixa efetividade no tratamento antimicrobiano já foi relatada por Costa et al. (2000) e Santos e Fonseca (2007). A refratariedade de $A$. pyogenes aos tratamentos pode ser creditada à estrutura do piogranuloma mamário, constituído por cápsula de tecido conectivo que reveste os abscessos, além do denso conteúdo purulento, que limita os antimicrobianos convencionais a atingirem concentrações terapêuticas no interior do foco infeccioso (Ribeiro, 2008), ou mesmo pela viabilidade intracelular do microrganismo (Radostits et al., 2007).
Diante da ineficácia do tratamento convencional da mastite por $A$. pyogenes, recomenda-se a secagem das fêmeas acometidas, a ablação química dos quartos afetados, ou mesmo o descarte dos animais. Recomenda-se, também, a adoção de medidas gerais de controle e profilaxia nas propriedades, voltadas para microrganismos ambientais envolvidos na mastite, quais sejam: realização de pré-dipping, retirada periódica de matéria orgânica e sujidades do ambiente da pré e pós-ordenha, limpeza dos equipamentos de ordenha, oferecimento de alimentos na pósordenha e cloração da água utilizada na sala de ordenha (Fernandes et al., 2009). A secagem abrupta dos animais e a adoção da terapia da vaca seca também são recomendadas em rebanhos com grande número de animais acometidos (Costa et al., 1998, 2000; Radostits et al., 2007).

Palavras-chave: gado leiteiro, Arcanobacterium pyogenes, surto, mastite

\begin{abstract}
An uncommon outbreak of mastitis caused by Arcanobacterium pyogenes in 26 cows is reported. The epidemiological findings, clinical signs, microbiological exams, somatic cell count, in vitro susceptibility profile of strains, efficacy of intramammary treatment and control measures were discussed. Florfenicol (96.2\%), cefoperazona (92.3\%), cefaloxin (84.6\%) and ceftiofur (84.6\%) were the most effective antimicrobials, and neomicin (27.0\%) and enrofloxacin (17.4\%) the least effective antimicrobials.
\end{abstract}

Keywords: dairy cattle, Arcanobacterium pyogenes, outbreak, mastitis

\section{REFERÊNCIAS BIBLIOGRÁFICAS}

COSTA, E.O.; RIBEIRO, A.R.; WATANABE, E.T. et al. Infectious bovine mastits caused by environmental organisms. J. Vet. Med., v.45, p.65-71, 1998.

COSTA, E.O.; RIBEIRO, A.R.; WATANABE, E.T. et al. Mastite por Arcanobacterium pyogenes: surto em rebanho de gado de corte. Rev. Núcleo Apoio Pesq. Gland. Mamária Prod. Leiteira, v.1, p.08-12, 2000

PERFORMANCE standards for antimicrobial disk susceptibility test (CLSI-NCCLS). 8.ed. Pennsylvania: Clinical and Laboratory Standards Institute, 2003.

DOMINGUES, P.F.; FERREIRA, B.L.S.; GALDINO, M.C. et al. Mastite em bezerra por Arcanobacterium pyogenes - Relato de Caso. Rev. Vet. Zootec., v.15, p.257-262, 2008.
FERNANDES, M.C.; RIBEIRO, M.G.; SIQUEIRA, A.K. et al. Surto de mastite bovina causada por linhagens de Pseudomonas aeruginosa multirresistentes aos antimicrobianos. Arq. Bras. Med. Vet. Zootec., v.61, p.745-748, 2009

HILLERTON, J.E.; BRAMLEY, A. Infection following challenge of the lacting and dry udder of dairy cows with Actinomyces pyogenes and Peptostreptococcus indoliticus. Br. Vet. J., v.145, p.148-158, 1989.

HILLERTON, J.E.; BERRY, E. A. Treating mastitis in the cow - a tradition or an archaism. J. Appl. Microbiol., v.98, p.1250-1255, 2005.

QUINN, P.J.; MARKEY, B.K., CARTER, M.E. et al. Microbiologia veterinária e doenças infecciosas. Porto Alegre: Artmed, 2005. 512p. 
RADOSTITS, O.M.; GAY, C.C.; HINCHCLIFF, K.W. et al. Veterinary medicine: a textbook of the diseases of cattle, horses, sheep, pigs, and goats. 10.ed. Philadelphia: Saunders, 2007. 2156p.

RIBEIRO, M.G. Princípios terapêuticos na mastite em animais de produção e de companhia. In: ANDRADE, S.F. (Ed.). Manual de terapêutica veterinária. 3.ed. Roca: São Paulo, 2008. p.759-771.
SANTOS, M.V.; FONSECA, L.F.L. Estratégias para controle de mastite e melhoria da qualidade do leite. São Paulo: Manole, 2007. 314p.

WILSON, D.J.; GONZALES, R.N.; DAS, H.H. Bovine mastitis pathogens in New York and Pensilvania: prevalence and effects on somatic cell count and milk production. J. Dairy Sci., v.80, p.2592-2597, 1997. 